\title{
Associative learning phenomena in the snail (Helix aspersa): Conditioned inhibition
}

\author{
Félix Acebes • Patricia Solar • Joaquín Moris • \\ Ignacio Loy
}

Published online: 30 August 2011

(C) Psychonomic Society, Inc. 2011

\begin{abstract}
Two experiments using garden snails (Helix aspersa) showed conditioned inhibition using both retardation and summation tests. Conditioned inhibition is a procedure by which a stimulus becomes a predictor of the absence of a relevant event - the unconditioned stimulus (US). Typically, conditioned inhibition consists of pairings between an initially neutral conditioned stimulus, $\mathrm{CS}_{2}$, and an effective excitatory conditioned stimulus, $\mathrm{CS}_{1}$, in the absence of the US. Retardation and summation tests are required in order to confirm that $\mathrm{CS}_{2}$ has acquired inhibitory properties. Conditioned inhibition has previously been found in invertebrates; however, these demonstrations did not use the retardation and summation tests required for an unambiguous demonstration of inhibition, allowing for alternative explanations. The implications of our results for the fields of comparative cognition and invertebrate physiological models of learning are discussed.
\end{abstract}

Keywords Conditioning - Conditioned inhibition · Snail . Associative learning $\cdot$ Cognition $\cdot$ Invertebrate

The study of learning processes in invertebrate species is relevant for a number of reasons. For example, they contribute to increasing and improving the evidence available for a comparative view of cognition (Wasserman, 1984) and have

F. Acebes $\cdot$ P. Solar $\cdot$ I. Loy $(\bowtie)$

Departamento de Psicología, Universidad de Oviedo,

Plaza Feijoo,

33003 Oviedo, Spain

e-mail: iloy@uniovi.es

J. Moris

Departamento Psicología Básica, Universidad de Málaga,

29071 Málaga, Spain

e-mail: jmoris@uma.es proven instrumental for enhancing our understanding of the physiological bases of learning and memory (Burrell \& Sahley, 2001; Carlson, 1994): The less complex central nervous system of invertebrates makes them suitable for assessing the biological bases of learning and memory at the neuronal and molecular levels (Crow, 2004).

Many instances of excitatory conditioning and other associative learning phenomena have been shown in invertebrate species; for example, sensory preconditioning, second-order conditioning, latent inhibition, overshadowing, and blocking have been observed in the common snail (Helix aspersa) using an appetitive excitatory conditioning procedure (Acebes, Solar, Carnero, \& Loy, 2009; Loy, Fernández, \& Acebes, 2006; for a review, see Farley, Jin, Huang, \& Kim, 2004) This research allows for abridging the research on learning phenomena at three different levels: (1) the development of formal learning theories, (2) comparisons of the learning abilities of different species across the evolutionary tree, and (3) the study of the physiological correlates of learned changes in the behaviour of animals.

Conditioned inhibition is a type of associative learning in which a subject learns that one stimulus signals the absence of another. Pavlov was the first author to describe a conditioned inhibition procedure (Pavlov, 1927). This procedure consists of a training in which a conditioned stimulus, $\mathrm{CS}_{1}$, is paired with an unconditioned stimulus (US) - an excitatory conditioning procedure; these excitatory conditioning trials are alternated with presentations of $\mathrm{CS}_{1}$ in a compound with a neutral stimulus, $\mathrm{CS}_{2}$, without the US. As a consequence of this manipulation, $\mathrm{CS}_{2}$, the nonreinforced $\mathrm{CS}$ of the compound, becomes a conditioned inhibitor. Producing convincing evidence that the $\mathrm{CS}_{2}$ is an effective conditioned stimulus - that is, a signal for the absence of the US - can be 
difficult. According to Rescorla (1969), an unambiguous demonstration of conditioned inhibition should involve evidence coming from both retardation and summation tests. In the retardation test, the putative inhibitor is repeatedly paired with the US; if it is an effective inhibitor, the acquisition of this new excitatory conditioning should be slower than excitatory conditioning of a new neutral CS. In the summation test, the putative inhibitor should reduce the magnitude of the conditioned response (CR) to a known excitor when they are presented in a compound. The slower acquisition of excitatory conditioning in the retardation test could be explained by a decrease in the attention paid to the putative inhibitor; conversely, the reduced CR obtained in the summation test could be explained by an increase in the attention paid to the putative inhibitor at the cost of the attention given to the excitor. Therefore, obtaining evidence from both retardation and summation tests is requisite for a reliable demonstration of conditioned inhibition that rules out alternative explanations - attention to the putative inhibitor cannot be simultaneously increased and decreased by inhibition training (e.g., Savastano, Cole, Barnet, \& Miller, 1999).

The study of conditioned inhibition has been key in the development of formal learning theories. A conventional interpretation of conditioned inhibition assumes that, in a particular procedure, if the probability of the US in the presence of the CS is higher than the probability of the US in the absence of the CS, this would result in excitatory conditioning; however, if the probability of the US in the presence of the CS is lower than in its absence, then inhibitory conditioning should be observed. This view of excitation and inhibition implies that both outcomes are opposite ends of a single associative value continuum and, consequently, that excitatory and inhibitory associations are mutually exclusive (e.g., Rescorla \& Wagner, 1972). However, it has been shown that, under certain conditions, a single stimulus can possess both excitatory and inhibitory properties (Droungas \& LoLordo, 1994; see Savastano et al., 1999, for a review). A more integrative view would assume the existence of different inhibitory processes at work during the learning experience. The more traditional approach states that inhibitory conditioning results in the establishment of an inhibitory association between the CS and the US. This alone would not account for the many instances of inhibitory conditioning available in the literature. Conditioned inhibition could also result in the establishment of an inhibitory association between the CS and the CR (e.g., Hull, 1943; Pavlov, 1927) or a positive association between the CS and the no-US representation (Konorski, 1967; Pearce, 1987; Rescorla, 1975), or it might result in a negative occasion setting (Rescorla, 1985). In contrast, the comparator hypothesis suggests that the concept of inhibition could be explained more parsimoniously by reference to noninhibitory mechanisms (e.g., Savastano et al., 1999). The nature of the processes that modulate conditioned inhibition is an ongoing matter for debate (e.g., Savastano et al., 1999) and can be considered to be a fundamental issue for current theories of learning. Improving our understanding of the mechanisms that rule inhibitory conditioning would enhance our knowledge about the general laws of learning.

The research of conditioned inhibition has also been relevant for the understanding of the physiological correlates of associative learning. Nicholson and Freeman (2002) noted that although much progress has been made at delineating the neural systems and the processes underlying simple excitatory classical conditioning, there is almost no research aiming at the physiological bases of conditioned inhibition. This is troubling, according to Nicholson and Freeman, because of the relevance of conditioned inhibition for the validation of influential formal models of associative learning. Britton and Farley (1999) stated that the physiological correlates of conditioned inhibition are "obscure and unexplored"; they suggest that more research is needed on conditioned inhibition in invertebrate models, which would provide a good start point to undertake research on its physiological correlates.

Conditioned inhibition has been studied with a proboscis conditioning procedure in European honeybees (Bitterman, Menzel, Fietz, \& Schäfer, 1983). This study showed evidence of retardation in acquisition after an explicitly unpaired training between an odour (the CS) and a sucrose solution (the US) delivered to the antennae in a signalled avoidance procedure. Abramson and Aquino (2002) found similar results by using Africanized honeybees. The retardation effect using differential inhibition can be explained by reference to a change in the excitatory value of the context, a process that does not involve true inhibitory learning (e.g., Couvillon, Bumanglag, \& Bitterman, 2003). In an experimental series using honeybees and two different appetitive procedures (proboscis-extension conditioning and free-flying foragers), Bitterman and his colleagues (Couvillon, Ablan, \& Bitterman, 1999; Couvillon, Ablan, Ferreira, \& Bitterman, 2001; Couvillon, Hsiung, Cooke, \& Bitterman, 2005) compared the Pavlovian inhibition ( $\left.\mathrm{CS}_{1}-\mathrm{US} / \mathrm{CS}_{1} \mathrm{CS}_{2}-\mathrm{NoUS}\right)$ and differential inhibition $\left(\mathrm{CS}_{1}-\mathrm{US} / \mathrm{CS}_{2}-\mathrm{NoUS}\right)$ procedures. Several authors (Pearce \& Kaye, 1985; Rescorla, 1979) have shown that rats trained using Pavlovian inhibition showed higher conditioned inhibition than animals trained according to the differential inhibition procedure. Bitterman and colleagues suggested that different procedures might result in similar outcomes due to the action of different mechanisms: true inhibition in the Pavlovian procedure, and context conditioning in the differential 
procedure. However, their work revealed no differences between the two inhibitory trainings, and in spite of the fact that different mechanisms could account for the results observed when using proboscis-extension conditioning or free-flying forager procedures, they concluded that the whole pattern of results could only be explained by reference to the establishment of true inhibitory conditioning (Couvillon et al., 2003, p. 367). Therefore, conditioned inhibition has been shown in invertebrate learning using bees, but only when using a retardation test. Following the suggestions of Bitterman and his colleagues, it seems to be worthwhile to produce more convincing evidence supported by both the retardation and summation tests and incorporating the relevant control conditions in order to assess alternative explanations.

Inhibitory processes have also been shown in other species of invertebrates. For example, Britton and Farley (1999), using Hermissenda crassicornis, have shown that animals that had received explicitly unpaired presentations of light (CS) and rotation (an aversive US) showed less withdrawal from light (phototactic suppression) than control animals that were not exposed to this training. This can be taken to be evidence for the inhibitory properties of the light stimulus, which signals the absence of an unpleasant event. Again, it would be worth finding additional evidence about the inhibitory properties of conditioned stimuli in invertebrate species by using other training procedures (such as Pavlov's original procedure), and especially using standard retardation and summation tests (e.g., Papini \& Bitterman, 1993; Rescorla, 1969; Williams, Overmier, \& LoLordo, 1992).

The objective of the experiments reported below was to find evidence of conditioned inhibition in an invertebrate species, garden snails, by using an appetitive conditioning preparation. In our experiments, animals were trained to anticipate the presentation of food by using odours. That is, the CSs were odours, the USs were food, and the CR was the number of tentacle lowering responses. In both experiments, snails experienced a compound of two odours without any consequences, and one of these odours was then followed by food. In Experiment 1, the nonpaired odour was conditioned as an excitatory CS-in other words, it explored conditioned inhibition by means of a retardation test-whilst in Experiment 2 we used a summation test.

\section{Experiment 1}

Experiment 1 aimed to test conditioned inhibition in snails by using the Pavlovian conditioned inhibition procedure and a retardation test. The Inhibition group was given Pavlovian inhibitory training by presenting two types of trials interspersed: training trials in which a conditioned stimulus, $\mathrm{CS}_{1}$, was paired with an unconditioned stimulus (US), and presentations of $\mathrm{CS}_{1}$ in a compound with a neutral stimulus, $\mathrm{CS}_{2}$, without the US. The retardation test involved pairings of the putative conditioned inhibitor, $\mathrm{CS}_{2}$, with the US for a number of trials. There were three control groups in this experiment: group Naïve, group Uncorrelated, and group New Element (see Table 1). The Naïve group was not given inhibitory training, which allowed us to compare simple excitatory conditioning of a neutral stimulus (in the Naïve group) with conditioning of a supposedly inhibitory stimulus (the Inhibition group). The Uncorrelated group received uncorrelated presentations of $\mathrm{CS}_{1}$ and US interspersed with $\mathrm{CS}_{1}-\mathrm{CS}_{2}$; in that way, we equated the experience with all of the stimuli in the Inhibition and the Uncorrelated groups, ruling out the possibility that reduced responding to $\mathrm{CS}_{2}$ in the Inhibition group is merely the result of a loss of effectiveness of the US. The New Element control group received $\mathrm{CS}_{3}-\mathrm{US}$ pairings interspersed with $\mathrm{CS}_{1}-\mathrm{CS}_{2}$ pairings in the conditioned inhibition training phase. This group was a control for the possibility that in the Uncorrelated control group excitatory contextual conditioning could take place, which would make the interpretation of the results rather difficult; for example, the greater conditioned responding in the Uncorrelated group relative to both the experimental group and the Naïve controls might well be due to context conditioning resulting from the uncorrelated CS-US presentations. One more useful point of introducing the New Element control group was that these animals would receive a kind of differential inhibition training $\left(\mathrm{CS}_{3} \rightarrow \mathrm{US} / \mathrm{CS}_{1}-\mathrm{CS}_{2} \rightarrow \mathrm{NoUS}\right)$. This group would be functionally equivalent to the Differential Inhibition group employed by Couvillon et al. (2005) and would allow us to test in another invertebrate species the same predictions.

A retardation test followed inhibitory training; if the $\mathrm{CS}_{2}$ had become inhibitory due to the Pavlovian conditioned inhibition training, then the excitatory conditioning of $\mathrm{CS}_{2}$ should be slower in the Inhibition group than in all the other groups.

Table 1 Design of Experiment 1

\begin{tabular}{lllll}
\hline Group & Inhibitory Training & 2nd Cond. & Test \\
\hline Inhibition & $6 \mathrm{CS}_{1}-\mathrm{CS}_{2}$ & $6 \mathrm{CS}_{1} \rightarrow \mathrm{US}$ & $6 \mathrm{CS}_{2} \rightarrow \mathrm{US}$ & $3 \mathrm{CS}_{2}$ \\
Naïve & & & $6 \mathrm{CS}_{2} \rightarrow \mathrm{US}$ & $3 \mathrm{CS}_{2}$ \\
Uncorrelated & $6 \mathrm{CS}_{1}-\mathrm{CS}_{2}$ & $6 \mathrm{CS}_{1} / \mathrm{US}$ & $6 \mathrm{CS}_{2} \rightarrow \mathrm{US}$ & $3 \mathrm{CS}_{2}$ \\
New Element & $6 \mathrm{CS}_{1}-\mathrm{CS}_{2}$ & $6 \mathrm{CS}_{3} \rightarrow \mathrm{US}$ & $6 \mathrm{CS}_{2} \rightarrow \mathrm{US}$ & $3 \mathrm{CS}_{2}$ \\
\hline
\end{tabular}

Arrows $(\rightarrow)$ indicate simultaneous presentation, whereas bars (/) indicate uncorrelated presentations. $\mathrm{CS}_{1}$ was apple for the first half of each group and pear for the other half; $\mathrm{CS}_{2}$ was pear for the first half of each group and apple for the other half; and $\mathrm{CS}_{3}$ was strawberry. The US was always carrot 


\section{Method}

Subjects The subjects were 80 snails taken from the wild, with an average shell diameter of $27 \mathrm{~mm}$ (range 20-33 mm) at the start of the experiment. The snails were individually housed in plastic cages $(50 \mathrm{~mm}$ long x $50 \mathrm{~mm}$ wide $\mathrm{x}$ $100 \mathrm{~mm}$ high) with air holes and a small amount of water and were situated in a cool dark room $\left(20^{\circ} \pm 2^{\circ} \mathrm{C}\right)$. They were given access to rat food for 2 days and then deprived of food for 10 days prior to the start of the experiment. During the experiment, snails only ate during conditioning.

Apparatus A plastic perforated tray $(500 \times 250 \mathrm{~mm}$, with 2.5-mm diameter holes) was used. It was supported at each corner above the table ( $60 \mathrm{~mm}$ above the surface) to allow a sample of fruit to be placed beneath the perforated tray. The experimental room was maintained at approximately $20^{\circ} \mathrm{C}$ and illuminated with a red light $(60 \mathrm{~W})$. The CSs employed in the present experiments were odours coming from pieces of fresh fruit: apple and pear were used as $\mathrm{CS}_{1}$ and $\mathrm{CS}_{2}$, whereas strawberry was used as $\mathrm{CS}_{3}$ (see the experimental design in Table 1). The fruit was presented on a plastic plate (280 $\mathrm{mm}$ in diameter) that was put under the plastic tray. The US was a small piece of carrot $\left(1 \mathrm{~cm}^{2}\right.$ approx. $)$ that was located on the plastic tray by the snail. Previous research (Acebes et al., 2009; Loy et al., 2006) has demonstrated no differences in the CRs given to the different CSs at the beginning of a conditioning phase or in the course of conditioning when associated with the US. Despite this, the roles of the CSs $\left(\mathrm{CS}_{1}-\mathrm{CS}_{2}\right)$ were counterbalanced; we ran the experiment twice and merging the data in the analysis, as no significant differences were observed between them. Thus, half of the animals of each group received apple odour as $\mathrm{CS}_{1}$ and pear odour as $\mathrm{CS}_{2}$, and the other half received pear odour as $\mathrm{CS}_{1}$ and apple odour as $\mathrm{CS}_{2}$.

Procedure After the 10-day deprivation period, the snails were randomly assigned to four equal-sized groups $(n=$ 20). Due to the experimental deaths of two snails, at the end of the experiment the Naiive group consisted of 18 animals. Immediately prior to each session, the snails were dipped in water and placed on their sides to induce activity. Once the snail had emerged from its shell, it was placed onto the perforated tray. After the session, the snail was returned to its container. During the first phase of the experiment, which lasted 2 days, animals in the Inhibition group were exposed to two different types of trials. First, animals were exposed to the $\mathrm{CS}_{1}$ odour while given access to carrot for $2 \mathrm{~min}$ (the US). The snail was allowed to eat for $2 \mathrm{~min}$ and was subsequently returned to its home cage; after $58 \mathrm{~min}$ (the intertrial interval, ITI), animals were exposed to the apple-pear compound for 2 min without access to food $\left(\mathrm{CS}_{1} \mathrm{CS}_{2} \rightarrow\right.$ NoUS trials). These two types of trials were then repeated twice each day with an ITI of $58 \mathrm{~min}$. Animals in the Uncorrelated group received trials consisting of $2 \mathrm{~min}$ of exposure to $\mathrm{CS}_{1}$ odour (either apple or pear) alone; $30 \mathrm{~min}$ after exposure to the odour, they were allowed to eat a piece of carrot for $2 \mathrm{~min}$ on the perforated tray. Another $28 \mathrm{~min}$ later, they were exposed to the $\mathrm{CS}_{1}-\mathrm{CS}_{2}$ compound as in the Inhibition group. This was then repeated twice during each session. As a result of that, animals in the Inhibition group had received six trials of simple apple or pear odour conditioning and six interspersed apple-pear compound odour trials. Animals in the Uncorrelated group had received six compound trials, as well as six exposures to apple or pear odour, and six separated exposures to the carrot US. Animals in the New Element group received six compound trials and six conditioning trials in which animals were exposed to strawberry while given access to the carrot US for $2 \mathrm{~min}$. Animals in the Naïve group received no treatment during these 2 days.

The subsequent 3 days constituted the retardation test phase of the experiment. The retardation test involved interspersed excitatory conditioning trials with $\mathrm{CS}_{2}$ (the putative conditioned inhibitor) and test trials in which $\mathrm{CS}_{2}$ was presented alone (ITI $=58 \mathrm{~min}$ ). Each day, animals received two trials consisting of access to a piece of carrot for $2 \mathrm{~min}$ in the presence of $\mathrm{CS}_{2}$, and then one test trial in which $\mathrm{CS}_{2}$ (pear or apple) was presented alone. In each test trial, tentacle lowering, the $\mathrm{CR}$, was registered in the presence of the $\mathrm{CS}_{2}$. Following Ungless's procedure (see Ungless, 2001, Fig. 2, p. 99), we scored as one conditioned response the movement of the tentacle below an imaginary line over the top of the head. Only the snail's left posterior tentacle was observed, in order to simplify the testing procedure. The number of responses was recorded for $2 \mathrm{~min}$ during the stimulus presentation. The snails were tested in random order by an experimenter unaware of their experimental history.

\section{Results and discussion}

Figure 1 shows the mean numbers of tentacle lowering responses made by the snails when the putative inhibitor odour $\left(\mathrm{CS}_{2}\right)$ was presented on each of the three test trials. Means for the first and second trials showed fewer CRs in the Inhibition group than in the other three groups. An ANOVA with group and trial as factors showed significant effects of trial $[F(2,148)=23.14, p<.05]$, and group $[F$ $(3,74)=9.77, p<.05]$, as well as a significant group $\mathrm{x}$ trial interaction $[F(6,148)=3.00, p<.05]$. Further analyses of this interaction, simple main effects, revealed significant differences between groups in the first two trials $[F(3,79) \geq 4.17, p<.05]$; the groups did not differ in 


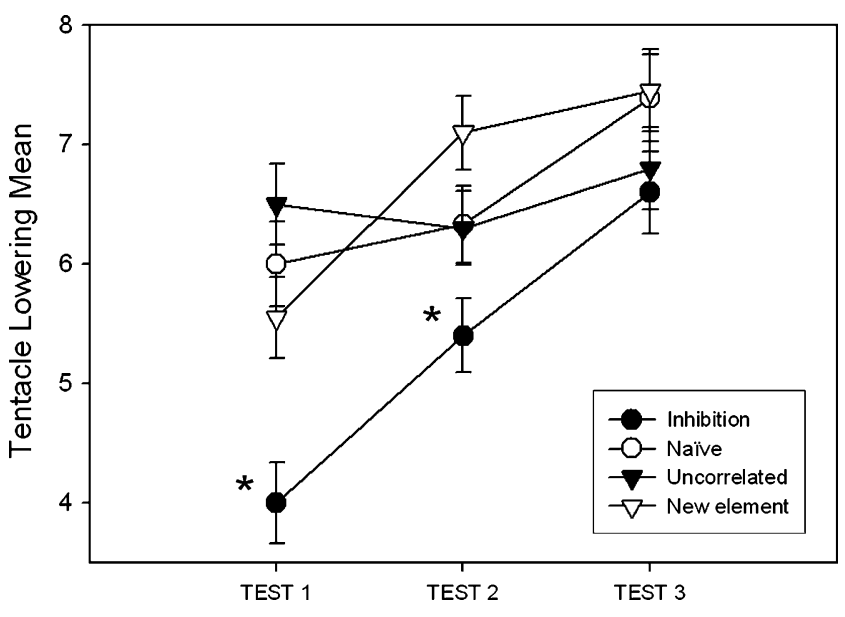

Fig. 1 Results of Experiment 1: Mean number of tentacle lowering responses made by each group during the three $\mathrm{CS}_{2}$ test trials. Vertical bars represent the standard errors of the mean $(S E M)$. ${ }^{*}$ Differences between group Inhibition and other groups, $p<.05$

the third test trial. Post-hoc analyses showed that during the first test trial, the Inhibition group differed from the three control groups $[t \mathrm{~s}(38) \geq 3.56, p<.05]$. During the second test trial, the Inhibition group significantly differed from the Uncorrelated and the New Element groups $[t \mathrm{~s}(38) \geq$ $2.74, p \mathrm{~s}<.05]$. No differences were found between the three control groups in any of the test trials. Given that test and conditioning trials were interspersed, the differences obtained diminished as conditioning advanced.

The present results support the hypothesis that the $\mathrm{CS}_{2}$ acquired the properties of an effective conditioned inhibitor in the Inhibition group, which retarded subsequent excitatory conditioning when the $\mathrm{CS}_{2}$ was paired with the carrot US.

\section{Experiment 2}

Experiment 1 successfully showed evidence of conditioned inhibition by using a retardation test. However, in a retardation test, a presumably inhibitory CS could behave as a conditioned inhibitor even if no inhibitory conditioning had taken place - for example, if the snail simply learned to ignore the CS or if the CS became a very weak excitor of the US (e.g., Hall \& Pearce, 1979). Therefore, a retardation test by itself does not provide unequivocal evidence for conditioned inhibition. Uncontroversial evidence for conditioned inhibition in our invertebrate model would require additional data coming from a summation test. Experiment 2 assessed whether, after Pavlovian conditioned inhibition training, a summation test would also show conditioned inhibition in snails (see Table 2). We replicated the Pavlovian inhibition training used in Experiment 1, except that the New Element group received slightly different
Table 2 Design of Experiment 2

\begin{tabular}{lllll}
\hline Group & Inhibitory Training & 2nd Cond. & Tests \\
\hline Inhibition & $6 \mathrm{CS}_{1}-\mathrm{CS}_{2}$ & $6 \mathrm{CS}_{1} \rightarrow \mathrm{US}$ & $6 \mathrm{CS}_{3} \rightarrow \mathrm{US}$ & $\mathrm{CS}_{3} \mathrm{CS}_{2}-\mathrm{CS}_{3}$ \\
Naïve & & & $6 \mathrm{CS}_{3} \rightarrow \mathrm{US}$ & $\mathrm{CS}_{3} \mathrm{CS}_{2}-\mathrm{CS}_{3}$ \\
Uncorrelated & $6 \mathrm{CS}_{1}-\mathrm{CS}_{2}$ & $6 \mathrm{CS}_{1} / \mathrm{US}$ & $6 \mathrm{CS}_{3} \rightarrow \mathrm{US}$ & $\mathrm{CS}_{3} \mathrm{CS}_{2}-\mathrm{CS}_{3}$ \\
New Element & $6 \mathrm{CS}_{1}-\mathrm{CS}_{2}$ & $6 \mathrm{CS}_{1} \rightarrow \mathrm{US}$ & $6 \mathrm{CS}_{3} \rightarrow \mathrm{US}$ & $\mathrm{CS}_{3} \mathrm{CS}_{4}-\mathrm{CS}_{3}$
\end{tabular}

Arrows $(\rightarrow)$ indicate simultaneous presentation, whereas bars (/) indicate uncorrelated presentations. $\mathrm{CS}_{1}$ was apple for the first half of each group and pear for the other half; $\mathrm{CS}_{2}$ was pear for the first half of each group and apple for the other half; $\mathrm{CS}_{3}$ was strawberry, and $\mathrm{CS}_{4}$ was banana. The US was always carrot.

training due to the summation test; this was followed by a summation test: All of the groups were given conditioning trials with a new $\mathrm{CS}_{3}$ (strawberry), and the tentacle lowering $\mathrm{CR}$ was registered in the presence of the $\mathrm{CS}_{3}$ (Test 1) and in the presence of the compound $\mathrm{CS}_{2}-\mathrm{CS}_{3}$ (or $\mathrm{CS}_{4}-\mathrm{CS}_{3}$, in New Element group). Therefore, Test 2 involved the putative inhibitor and a known excitor. If the $\mathrm{CS}_{2}$ had acquired the properties of an effective conditioned inhibitor in the Inhibition group, it should cause a decrease in responding in the $\mathrm{CS}_{2}-\mathrm{CS}_{3}$ compound trial as compared to the $\mathrm{CS}_{3}$ trial. On the other hand, this should not happen (to the same extent) in the Naïve, Uncorrelated, and New Element controls.

\section{Method}

Subjects The subjects were 80 snails taken from the wild, with an average shell diameter of $26 \mathrm{~mm}$ (range 20-29 mm) at the start of the experiment. All of the housing and maintenance details were exactly the same as those described for Experiment 1.

Procedure After the 10-day deprivation period, the snails were randomly assigned to four equal-sized groups $(n=$ 20 ). Due to the experimental death of 8 snails, at the end of the experiment the final sizes of the groups were $n=19$ for the Inhibition and New Element groups, $n=18$ for the Naïve group, and $n=16$ for the Uncorrelated group. The inhibition training procedure replicated the one described in Experiment 1, except for the New Element group, which received exactly the same treatment as the Inhibition group. The apple and pear odours were used as CSs (counterbalanced in two replicas) as in Experiment 1. During the summation test, all of the animals were given six $\mathrm{CS}_{3}-\mathrm{US}$ conditioning trials, where $\mathrm{CS}_{3}$ was the strawberry odour. During the last day of the experiment, snails in the Inhibition, Uncorrelated, and Naïve groups were individually tested in the presence of the $\mathrm{CS}_{2}-\mathrm{CS}_{3}$ compound and in the presence of $\mathrm{CS}_{3}$ alone. Snails in the New Element group 
were tested in the presence of the $\mathrm{CS}_{4}-\mathrm{CS}_{3}$ compound (where $\mathrm{CS}_{4}$ refers to a new odour, banana) and $\mathrm{CS}_{3}$ alone. A total of 10 subjects from each group were first tested with the compound, and $1 \mathrm{~h}$ later with the element. The remaining subjects in each group were tests in the reverse order.

\section{Results and discussion}

The results of the summation test are displayed in Fig. 2. Only in the Inhibition group was a difference detected between the number of CRs recorded to the element $\left(\mathrm{CS}_{3}\right)$ and to the compound $\left(\mathrm{CS}_{2}-\mathrm{CS}_{3}\right)$. A repeated measures ANOVA with test odour (element or compound) and group as factors showed a significant group $\mathrm{x}$ test odour interaction $[F(3,68)=13.20, p<.05]$. Neither of the main factors reached significance. Further analyses were carried out to analyse the group $\mathrm{x}$ test odour interaction. Two ANOVAs carried out on the data coming from the compound $\left(\mathrm{CS}_{2}-\mathrm{CS}_{3}\right)$ and the element $\left(\mathrm{CS}_{3}\right)$ tests showed a significant difference between groups in the compound test $[F(3,71)=11,96, p<.05]$ and revealed a null result when considering the element test. Further analyses revealed that animals in the Inhibition group showed fewer responses than any of the three control groups $[t s$ (33) $\geq 2.93, p s<.05]$. Finally, we observed a significant difference between the element test $\mathrm{CS}_{3}$ and the compound test $\left(\mathrm{CS}_{2}-\mathrm{CS}_{3}\right)$ only in the Inhibition group $[t(18)=6.39$, $p<.05]$. The present results show that, in the Inhibition group, the presence of the conditioned inhibitor reduced the magnitude of the $\mathrm{CR}$ during the compound test $\left(\mathrm{CS}_{2}-\right.$ $\mathrm{CS}_{3}$ ). Taken together with the results of Experiment 1, the

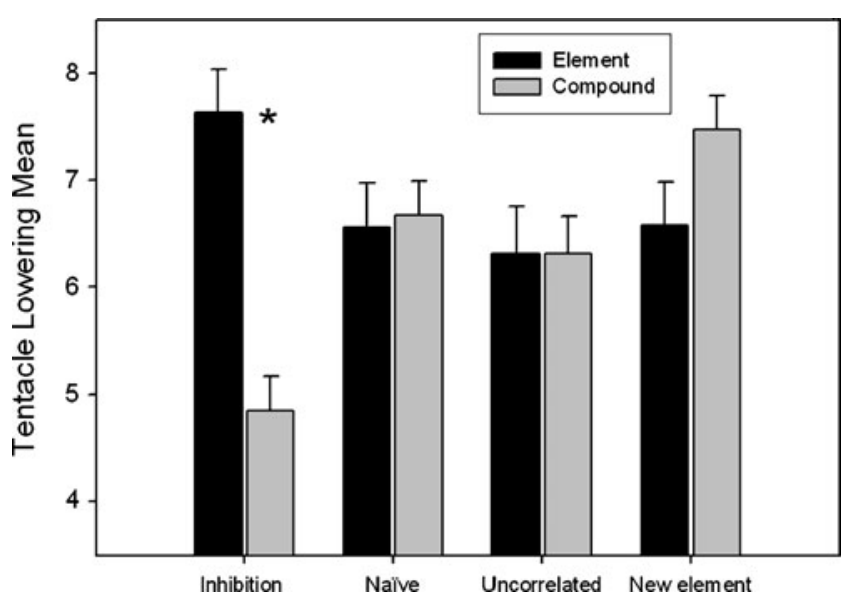

Fig. 2 Results of Experiment 2: Mean number of tentacle lowering responses of each groups in a single element test trial $\left(\mathrm{CS}_{3}\right)$ and in a compound test trial $\left(\mathrm{CS}_{2}-\mathrm{CS}_{3}\right.$ or $\left.\mathrm{CS}_{4}-\mathrm{CS}_{3}\right)$. Vertical bars represent the standard error of the mean $(S E M)$. *Difference between group Inhibition and other groups, $p<.05$ present results can be considered unequivocal evidence for conditioned inhibition in an invertebrate model.

\section{General discussion}

In two experiments, garden snails were trained in a Pavlovian task. Animals learned to anticipate the presentation of food by using odours as signals, and the tentacle lowering response (e.g., Ungless, 2001) was used as an index of this learning. In Experiment 1, snails given inhibitory training following the Pavlovian procedure $\left(\mathrm{CS}_{1} \rightarrow \mathrm{US} / \mathrm{CS}_{1}-\mathrm{CS}_{2} \rightarrow \mathrm{NoUS}\right)$ were slower than controls at developing a conditioned response to the putative conditioned inhibitor, the $\mathrm{CS}_{2}$ element-a retardation test for conditioned inhibition. Experiment 2 replicated the results of Experiment 1 using a summation test. Taken together, the results of Experiments 1 and 2 provide unequivocal evidence of conditioned inhibition in snails: Training in the Pavlovian conditioned inhibition procedure led snails in the experimental group to learn to anticipate the absence of the US.

The present results might be accounted for by taking into account other mechanisms; however, these alternative explanations are far less parsimonious. The present results cannot be explained as a whole, for example, by reference to a differential change in the salience or effectiveness of the US in the experimental and the control groups. Experience with the US was matched in the experimental group (given inhibitory training) and in two of the control groups (Uncorrelated and New Element); however, the Uncorrelated and New Element groups' performance was more similar to that exhibited by the Naïve group, which had no previous experience with the US before the retardation and summation tests, than to that exhibited by the experimental group in Experiments 1 and 2. Another factor that might account for the inhibition observed is experience with the experimental context. In both experiments, however, although exposure to the context was matched in the experimental group and the New Element control group, their performances were entirely different, casting doubts on the role of context in this particular set of experiments. A different potential source of confounding would be experience with the putative conditioned inhibitor, which is given nonreinforced preexposure during the inhibition training. Comparing, for example, the experimental and the Naïve groups, retardation of learning when the putative inhibitor was paired with the US could be said to be the consequence of latent inhibition. However, the New Element and Uncorrelated groups were given equivalent nonreinforced preexposure to the $\mathrm{CS}_{2}$ (the putative inhibitor), yet they performed similarly to the Naïve group. This seems to exclude latent 
inhibition as a valid explanation for the retardation effect. Moreover, this latent-inhibition account would fail to explain the results observed in Experiment 2, in which a summation test was used.

In an important study assessing inhibitory learning in honeybees, Couvillon et al. (2005) compared two different inhibitory procedures: conditioned inhibition, trained with a procedure very similar to the one used in the Inhibition group of our experiments, and an explicitly unpaired group, which was functionally equivalent to the procedure used in the New Element groups of the present study. According to the Rescorla-Wagner model (Rescorla \& Wagner, 1972), inhibitory learning should take place more readily in a Inhibition Group than in a New Element Group. This difference has been reported in experiments using vertebrates (e.g., Pearce \& Kaye, 1985; Rescorla, 1975). However, Couvillon et al. (2005) found no differences between these treatments in their invertebrate model-honeybees. In the experiments reported here a significant difference was observed between the Inhibition and New Element groups, as predicted by the Rescorla-Wagner model. A possible explanation for the discrepancy between our experiments and the study by Couvillon et al. (2005) is the fact that their task seemed to produce very high context conditioning, whereas our procedure seemed to produce very low context conditioning. The context could be a particularly good signal for the US in the Uncorrelated group of Experiments 1 and 2, as compared with groups Inhibition and New Element, in ehich the US was always signalled by a discrete $\mathrm{CS}\left(\mathrm{CS}_{1}\right.$ for the Inhibition group and $\mathrm{CS}_{3}$ or $\mathrm{CS}_{1}$ for the New Element group in Experiments 1 and 2, respectively). However, performance was practically identical in groups New Element and Uncorrelated, suggesting that the context did not play a significant role in our preparation.

To conclude, the experiments reported here constitute clear evidence of conditioned inhibition in an invertebrate species using an appetitive learning procedure. This is but one more step in an organized effort to replicate the relevant phenomena of associative learning in an invertebrate model (see Acebes et al., 2009; Loy et al., 2006; Ungless, 1998). This invertebrate model could be a useful instrument to use to further our understanding of the physiological bases of learning and memory. Our appetitive procedure is functionally equivalent to the typical procedures used in associative-learning research with vertebrates (e.g., magazine training in rats and autoshaping in pigeons). The usage of an invertebrate animal with a relatively simple nervous system might facilitate putting together the research on learning phenomena and the physiological mechanisms that are supposed to sustain associative learning. Our procedure could also be beneficial in comparisons of learning abilities and learning mechanisms among different species far separated in the evolutionary tree.

Author Note This research was supported by Ministerio de Ciencia e Innovación Español (SEJ 2007-63017 and PSI2011-25071) and Gobierno del Principado de Asturias (BP-08037). We thank John Pearce for helpful comments on early drafts of this manuscript. Susana Carnero and Beatriz Alvarez helped us with all the details of the experiments. Sandra Tellander improved the English and Jose Prados helped us to improve final drafts of the article.

\section{References}

Abramson, C. I., \& Aquino, I. S. (2002). The use of honey bees (Apis mellifera L.) to solve practical problems. International Journal of Comparative Psychology, 15, 30-48.

Acebes, F., Solar, P., Carnero, S., \& Loy, I. (2009). Blocking of conditioning of tentacle lowering in the snail (Helix aspersa). Quarterly Journal of Experimental Psychology, 62, 1315-1327. doi:10.1080/17470210802483545

Bitterman, M. E., Menzel, R., Fietz, A., \& Schäfer, S. (1983). Classical conditioning of proboscis extension in honeybees (Apis mellifera). Journal of Comparative Psychology, 97, 107-119. doi:10.1037/0735-7036.97.2.107

Britton, G., \& Farley, J. (1999). Behavioral and neural bases of noncoincidence learning in Hermissenda. Journal of Neuroscience, 19, 9126-9132.

Burrell, B. D., \& Sahley, C. L. (2001). Learning in simple systems. Current Opinion in Neurobiology, 11, 757-764. doi:10.1016/ S0959-4388(01)00281-1

Carlson, N. R. (1994). Physiology and behavior. Boston: Allyn \& Bacon.

Couvillon, P. A., Ablan, C. D., \& Bitterman, M. E. (1999). Exploratory studies of inhibitory conditioning in honeybees (Apis mellifera). Journal of Experimental Psychology. Animal Behavior Processes, 25, 103-112. doi:10.1037/0097-7403.25.1.103

Couvillon, P. A., Ablan, C. D., Ferreira, T. P., \& Bitterman, M. E. (2001). The role of nonreinforcement in the learning of honeybees. Quarterly Journal of Experimental Psychology, 54B, 127-144. doi:10.1080/713932747

Couvillon, P. A., Bumanglag, A. V., \& Bitterman, M. E. (2003). Inhibitory conditioning in honeybees. Quarterly Journal of Experimental Psychology, 56B, 359-370. doi:10.1080/ 02724990244000313

Couvillon, P. A., Hsiung, R., Cooke, A. M., \& Bitterman, M. E. (2005). The role of context in the inhibitory conditioning of honeybees. Quarterly Journal of Experimental Psychology, 58B, 59-67. doi:10.1080/02724990444000050

Crow, T. (2004). Pavlovian conditioning of Hermissenda: Current cellular, molecular, and circuit perspectives. Learning and Memory, 11, 229-238. doi:10.1101/1m.70704

Droungas, A., \& LoLordo, V. M. (1994). Evidence for simultaneous excitatory and inhibitory associations in the explicitly unpaired procedure. Learning and Motivation, 25, 1-25. doi:10.1006/ lmot.1994.1001

Farley, J., Jin, I., Huang, H., \& Kim, J. (2004). Chemosensory conditioning in molluscs: II. A critical review. Learning \& Behavior, 32, 277-288. doi:10.3758/BF03196027

Hall, G., \& Pearce, J. M. (1979). Latent inhibition of a CS during CSUS pairings. Journal of Experimental Psychology. Animal Behavior Processes, 5, 31-42. doi:10.1037/0097-7403.5.1.31

Hull, C. L. (1943). Principles of behavior, an introduction to behavior theory. New York: Appleton. 
Konorski, J. (1967). Integrative activity of the brain: An interdisciplinary approach. Chicago: University of Chicago Press.

Loy, I., Fernández, V., \& Acebes, F. (2006). Conditioning of tentacle lowering in the snail (Helix aspersa): Acquisition, latent inhibition, overshadowing, second-order conditioning, and sensory preconditioning. Learning \& Behavior, 34, 305-314. doi:10.3758/ BF03192885

Nicholson, D. A., \& Freeman, J. H., Jr. (2002). Neuronal correlates of conditioned inhibition of the eyeblink response in the anterior interpositus nucleus. Behavioral Neuroscience, 116, 22-36. doi:10.1037/0735-7044.116.1.22

Papini, M. R., \& Bitterman, M. E. (1993). The two-test strategy in the study of inhibitory conditioning. Journal of Experimental Psychology. Animal Behavior Processes, 19, 342-352. doi:10.1037/0097-7403.19.4.342

Pavlov, I. P. (1927). Conditioned reflexes (G. V. Anrep, Trans.). London: Oxford University Press.

Pearce, J. M. (1987). A model for stimulus generalization in Pavlovian conditioning. Psychological Review, 94, 61-73. doi:10.1037/ 0033-295X.94.1.61

Pearce, J. M., \& Kaye, H. (1985). Strength of the orienting response during inhibitory conditioning. Journal of Experimental Psychology. Animal Behavior Processes, 11, 405-420. doi:10.1037/00977403.11.3.405

Rescorla, R. A. (1969). Pavlovian conditioned inhibition. Psychological Bulletin, 72, 77-94. doi:10.1037/h0027760

Rescorla, R. A. (1975). Pavlovian excitatory and inhibitory conditioning. In W. K. Estes (Ed.), Handbook of learning and cognitive processes (Vol. 2, pp. 7-35). Hillsdale, NJ: Erlbaum.
Rescorla, R. A. (1979). Conditioned inhibition and extinction. In A. Dickinson \& R. A. Boakes (Eds.), Mechanisms of learning and motivation (pp. 83-110). Hillsdale, NJ: Erlbaum.

Rescorla, R. A. (1985). Conditioned inhibition and facilitation. In R. R. Miller \& N. E. Spear (Eds.), Information processing in animals: Conditioned inhibition (pp. 299-326). Hillsdale, NJ: Erlbaum.

Rescorla, R. A., \& Wagner, A. R. (1972). A theory of Pavlovian conditioning: Variations in the effectiveness of reinforcement and nonreinforcement. In A. H. Black \& W. F. Prokasy (Eds.), Classical conditioning II: Current research and theory (pp. 64-99). New York: Appleton.

Savastano, H. I., Cole, R. P., Barnet, R. C., \& Miller, R. R. (1999). Reconsidering conditioned inhibition. Learning and Motivation, 30, 101-127. doi:10.1006/lmot.1998.1020

Ungless, M. A. (1998). A Pavlovian analysis of food-attraction conditioning in the snail Helix aspersa. Animal Learning and Behavior, 26, 15-19. doi:10.3758/BF03199158

Ungless, M. A. (2001). Dissociation of food-finding and tentaclelowering, following food-attraction conditioning in the snail, Helix aspersa. Behavioural Processes, 53, 97-101. doi:10.1016/S03766357(01)00136-X

Wasserman, E. A. (1984). Animal intelligence: Understanding the minds of animals through their behavioural "ambassadors. In $\mathrm{H}$. L. Roitblat, T. G. Bever, \& H. S. Terrace (Eds.), Animal cognition (pp. 45-60). Hillsdale, NJ: Erlbaum.

Williams, D. A., Overmier, J. B., \& LoLordo, V. M. (1992). A reevaluation of Rescorla's early dictums about Pavlovian conditioned inhibition. Psychological Bulletin, 111, 275-290. doi:10.1037/00332909.111.2.275 